\title{
Contamination behaviour on the surface of building materials
}

\author{
B. Zlobenko, Yu. Fedorenko and E. Sobotovich \\ State Scientific Center of Environmental Radiogeochemistry, \\ Palladin Ave. 34a, Kyiv 03142, Ukraine
}

\begin{abstract}
Study of radionuclides penetration into building materials is connected with many difficulties of methodical character: difficult micro- and macro relief of the materials surface, rate of their weathering or growth on their surface of biogenic forms, a considerable variety of physical and mechanical properties of like building material. White and red bricks are considered to be the most spread building materials. Slate and tile were used as materials for roofs. Contaminated surface layer of building material samples was studied with three ways supplemented each other: 1) removing of building material layer by polishing-out; 2) measuring of activity of polished-out material layer after each treatment and simultaneously determining of a removed layer mass; 3) autoradiographical researches of radionuclide distribution on different cross-sections of building material samples. The biggest gradient of radionuclides concentration is observed in the layer of $70-80 \mathrm{~g} / \mathrm{m}^{2}$ mass. The coefficient of decontamination in this case is made up 1.5-1.6. The further removing of deeper layers gives lower effect of decontamination because a considerable amount of radionuclides is distributed in deeper layers of building materials. The most considerable changes of roughness when tile processing were observed after the first surface treatment. An average value of a removed layer were made up about $80 \mu \mathrm{m}$.
\end{abstract}

\section{INTRODUCTION}

In recent years significant research, both theoretical and experimental, has been directed towards gaining a better understanding of radionuclides deposition in urban areas and their subsequent behaviour [1-3]. Different constructions with premises for residing, cultural-household and industrial purposes can be referred to the main urbanized territory objects.

The typical contamination object begins with the contact of contamination and the object's surface. The surface can be formed by small elements (brick, stoneware, small units, etc.), by large elements (large blocks, panels, volumetric blocks) and by monolithic concrete units as well.

The surfaces of buildings and structures differ also in their constructive elements and materials, which are used at construction. The apertures of various kinds (windows, doors), as well as the roofs with coverings of different sorts (slate, galvanized and painted sheet steel, roofing felt, tile, and etc.) belong to the major elements.

The listed abundance of various surfaces complicates essentially a quantitative consideration of questions on radioactive pollution and migration of radionuclides and decontamination processes as well. It is connected first of all with the fact that different surfaces are not sufficiently divided into the certain types by their radioecological attributes, many of which are not designated precisely while having just ouly qualitative description. It concerns, first of all, to a roughness and porosity - the factors governing both pollution and radionuclides migration process.

The next main characteristics of the urbanized territory object surfaces that can have influence on radioactive pollution had been accentuated on the basis of buildings and structures investigations about pollution character:

1- surface inclination angle;

2- wetting marginal angle;

3- roughness of a surface;

4- near-surface layer porosity; 
5- surface fractal dimensions;

6- biogenic formations and processes on the surfaces;

7- technogenic impact for the surfaces previous and after their contamination with radioactivity.

It should be mentioned that these factors are mostly being interconnected and interdependent. For example, the fractal characteristics are connected to a surface roughness, biogenic formations (swagnum, moss) are developing the best on the inclined straw, wooden and slate surfaces (roofs), and wetting marginal angle depends on a surface nature, its porosity and roughness. However, in this case the serious difficulties arise at the definition stage from determination these characteristics for building materials up to their distribution for the large surfaces of objects (walls, roofs, and etc.). For example, gradation from silicate brick surface porosity to a wall surface porosity of silicate brick divided by limy-sandy joints, having convex striking, and etc. One of the principal features of a surface within the radioecological plan is its roughness.

The radionuclides behavior along the urbanized territory objects surfaces when being under more detailed consideration also had shown that the development of biogenic forms on the surface of building materials plays a large role in radioecological questions under the conditions of Polissia damp climate. First of all it concerns with swagnum and moss, which due to their features of anatomical and morphological structure, slow biomass increasing and destruction, their large sorption ability can catch and accumulate a significant part of radionuclides. The concentration of radioactive elements within these swagnums and mosses is $5-50$ times higher than that within the ground plants. The investigations carried out for the different mosses have shown that the greatest content comes to Cs-137, the highest accumulation ability is fixed for mosses, then swagnums come, bark of trees comes, defoliation, etc.

It is known that the building materials porosity plays the large role both at surface contamination by radionuclides and at migration investigation.

\section{EXPERIMENTAL WORKS OF MIGRATION STUDYING}

The research of radioactive contamination migration along the urbanized areas has shown, that radionuclides appeared on building materials surface are moving within the volume of material. The penetration degree depends on the form of radionuclides and on the state of building material sufface, which defines their retention ability. The assessment degree of radioactive contamination penetration within the materials has a huge importance first of all for the choice of decontamination way, which give; a peak efficiency. The definition of quantitative parameters for building material surface porosity makes up the important task at study of radionuclides distribution character, their migration orientation and speed. Examined parameters are only a part of those ones, which influence or can render their influence on the migration process. However, many of them can enter into the parameters directly or indirectly and to be taken into account by that during the analysis. So, for example, the kind of building materials, and etc. can be taken into consideration by the degree parameter of delay; the dependence upon the weather conditions can extend by many parameters, etc.

There is far less information of radioactive contamination different forms penetration into building materials which are distinguished by different composition, characteristics and functionality. Insufficient information presents also on factors promoting or preventing this process. At the same time the preliminary observation shows that study of radionuclides introduction process into building materials is connected with many difficulties of methodological nature: complex micro- and macro- relief of materials surface, the weathering degree either development biogenic forms on their surface, significant range in physico-mechanical characteristics of like building material that had been made from raw materials and according to different idustrial technologies.

What is more, a surface of building materials is not always plane, it has specific roughness, porosity, ability for moistening, that also influences upon radionuclides removing and ought to be taken in account when studying a mechanism of radionuclide interaction with decontaminating compositions.

Surface roughness can be quantitatively characterized by the most inequalities height $R_{\max }$ that $c$ an be defined by distance between the line of profile ledges and the line of profile depressions within the base length limits. Ledges line gets through the most height of ledge, but depressions line - through the greatest depth of profile depression. 
During surface polishing, when its microrelief is changing, roughness can be characterized by supporting length of profile, that presents itself an amount of sections lengths, to be cut off at a given level in profile material by line, equidistant to a centerline within base length 1 , marked $\eta_{p}$

$$
\eta_{p}=\sum_{i=1}^{n} b_{i}
$$

If a study as for radionuclides permeation is carried out on separate plane samples, the uncontaminated side of these samples can be polished beforehand and be used as a base plane, in respect to which the enumerated above features can be measured of consecutively deleted layers roughness or thickness.

In such cases, when polluted surface is not plane, difficulties can be appeared when a centerline, ledges and depressions lines are being drawn. Uncertainties with such lines undertaking can appear under mechanical processing of the surfaces, when the layers being removed consecutively from the twisted suface are not always to be of equal thickness.

At the choice of materials for study the fact used to be taken into consideration, that the most pidespread building materials were white and red brick, which can be covered with whitening several layers. The materials used in the most cases with the purpose to cover the roofs were: slate, tile and iron. Contaminated surface layer of building material samples had been studied by three complementary ways:

I - on forming a base plane in the samples and on getting the results about the distance of checkpoints on surfaces of material from this base plane the measurement of samples activity was put through with the $\beta$-radiometry, then the building material layer was removed by its polishing out. Since the surface of material is not plane, the thickness of removed layer was checked periodically, and it was corrected in such a way so that the most value could not be more than 2-3 times as large as the least value. Measurements are repeated successively after each procedure of the next external layer removing;

II - measurement of polished out material layer activity. Simultaneously a measurement had been producing of the sample being under study was carried out after each processing and determination of removed layer mass; samples.

III - autoradiographic studies, radionuclide distribution on the different cuts of building material

Application of several methods for investigation is stipulated by the following circumstance. Removing a building material layer by layer can be executed by several ways: cutting, pickling and etc. In the given work the external layers were consecutively removed by polishing with medium-grained waterresistant sand-paper. Under such a way of material removing from porous material surface there is always a certain probability for contamination of material deeper layers by radioactive substances, particularly in the event of material variegated contamination through the depth. A possible contamination of deeper layers can be reduced slightly if some small holes-traps can be done beforehand on the surfaces of material with the purpose to collect rubbed material. A role of such traps can be executed in the objective samples by large pores, caverns, cracks and etc. Depending on the distribution by particles sizes their certain part can reach to more deep pores and cracks. If they are the radioactive particles, a false effect of additional radionuclides migration deep in the material is created under spectrometry or $\beta$-radiometry.

\subsection{Autoradiographic studies}

The radiographic method on radioactive substance distribution study in the investigated objects allows to trace the anisotropic character of surface contamination. Geometric form of tile samples showed up the plates with sizes $65 \times 35 \times 12 \mathrm{~mm}$, of slate samples - $60 \times 30 \times 5 \mathrm{~mm}$. Autoradiographic photographs were made from the outside surface subjected to active effect of many factors, and from the side shear of surface being perpendicular to the first ones. The cross-cut of sample is made from the "net" to the "dirty" surfaces (fig 1,2). However, a refrigerant liquid, which enters the diamond circle under cutting the sample, can contribute some or other uncertainty, since washing out of activity certain part from the cross-cut surfaces becomes possible. 
The analysis of radiation intensity distribution picture has shown, that radionuclides penetrate practically through the tile whole thickness. The data from processing of photometric curves of flm blackening density distribution on the autoradiograms of tile and slate transversal shears are given in tables 1 and 2 . When the results are compared it is possible to make some conclusions.

Integral radionuclide radiation intensity is somewhat above in a tile, than in slate at exposure time being equal, but the distribution by depth differs essentially. The comparative data indicated in the tables point to the fact that the Laue curve width of radiation intensity distribution defined by S/Imax relation differs for slate and tile samples as well. It is possible to judge about the radionuclide deepening degree by value of this statistically average characteristic. Radionuclide deepening is more in tile samples, than il is in slate ones selected in the same district and at the same time.

Table 1 Evaluation of microdensitometric curve integral and maximum intensities plotted by autoradiograms of tile sample transversal shears.

\begin{tabular}{|l|c|c|c|c|c|c|c|}
\hline $\mathbf{N}^{\mathbf{0}}$ & $\mathbf{S}, \mathbf{c m}^{\mathbf{2}}$ & $\mathbf{I m a x}, \mathbf{c m}$ & $\mathbf{S} / \mathbf{I m a x}, \mathbf{c m}$ & $\mathbf{N}^{\mathbf{0}}$ & $\mathbf{S}, \mathbf{c m}^{\mathbf{2}}$ & $\mathbf{I m a x}, \mathbf{c m}$ & $\mathbf{S} / \mathbf{I m a x}, \mathbf{c m}$ \\
\hline 1. & 25 & 6.9 & 3.6 & 9 & 15 & 4.3 & 3.5 \\
\hline 2. & 15 & 9.0 & 1.7 & 10 & 17 & 4.8 & 3.5 \\
\hline 3. & 17 & 5.3 & 3.2 & 11 & 14 & 5.0 & 2.8 \\
\hline 4. & 12 & 3.0 & 4.0 & 12 & 17 & 4.8 & 3.5 \\
\hline 5. & 16 & 4.5 & 3.6 & 13 & 25 & 7.0 & 3.6 \\
\hline 6. & 20 & 6.2 & 3.2 & 14 & 9 & 2.4 & 3.8 \\
\hline 7. & 17 & 5.3 & 3.2 & 15 & 15 & 3.2 & 4.7 \\
\hline 8. & 26 & 9.8 & 2.6 & 16 & 26 & 9.4 & 2.7 \\
\hline
\end{tabular}

Table 2 Evaluation of microdensitometric curve integral and maximum intensities plotted by autoradiograms of slate sample transversal shears.

\begin{tabular}{|l|l|l|l|l|l|l|l|}
\hline $\mathbf{N}^{\mathbf{0}}$ & $\mathbf{S}, \mathbf{c m}^{2}$ & $\mathbf{I m a x}, \mathbf{c m}$ & $\mathbf{S} / \mathbf{I m a x}, \mathbf{c m}$ & $\mathbf{N}^{\mathbf{0}}$ & $\mathbf{S}, \mathbf{c m}^{\mathbf{2}}$ & $\mathbf{I m a x}, \mathbf{c m}$ & $\mathbf{S} / \mathbf{I m a x}, \mathbf{c m}$ \\
\hline 1 & 15 & 9.8 & 1.5 & 9 & 10 & 7.4 & 1.3 \\
\hline 2 & 15 & 14.5 & 1.0 & 10 & 16 & 8.8 & 1.8 \\
\hline 3 & 14 & 14.1 & 1.0 & 11 & 16 & 9.5 & 1.7 \\
\hline 4 & 17 & 15.5 & 1.09 & 12 & 14 & 9.0 & 1.6 \\
\hline 5 & 22 & 12.2 & 1.8 & 13 & 9 & 6.8 & 1.3 \\
\hline 6 & 12 & 8.0 & 1.5 & 14 & 11 & 7.2 & 1.5 \\
\hline 7 & 9 & 11.3 & 0.8 & 15 & 13 & 9.4 & 1.4 \\
\hline 8 & 23 & 15.5 & 1.5 & 16 & 12 & 7.7 & 1.6 \\
\hline
\end{tabular}

The analysis of irradiation intensity distribution picture has shown, that radionuclides penetrate practically through the tile whole thickness. The percentage ratio of I/Imax makes $27 \%$ on the average in $2 \mathrm{~mm}$ depth from the outside surface, surface stratum thickness being approximately $0,2-0,3 \mathrm{~mm}$ make $70 \%$ of radiation intensity. The heterogeneity of outside surface contamination has an effect for I max value.

Table 3. Definition of porosity for building material samples.

\begin{tabular}{|l|c|}
\hline Kind of material & $\mathbf{V n} / \mathbf{V}, \%$ \\
\hline Silicate brick & 27.8 \\
\hline Ceramic white plate & 6.3 \\
\hline Tile & 31.2 \\
\hline Slate & 16.7 \\
\hline
\end{tabular}


It is possible to explain various degree of radionuclide deepening within the building material samples selected after the Chornobyl disaster 10 years later from the point of view of sample surface various states, structure and composition content of materials, porosity, sorption and de-sorption processes happening under the meteorological factor effect. The results of porosity measurement as the relation between the pore volume and various building material sample volume are indicated in table 3 . The samples of silicate brick, white ceramic plate, slate, tile are investigated by standard technology of sample mass changing after their saturation with kerosene at room temperature.

\subsection{Migration study by removing material layers}

If the surface is sufficiently rough the polishing provides leveling of the plane in the initial moment due to removing of the most emerged roughness tops. More small roughness use to stay unchangeable, though a plane of polishing moves. As far as determination of exact quantitative correlation between these processes for stretched surfaces is sufficiently laborious, and extrapolation of data received on small platforms is small-reliable for the greater surfaces due to the absence of data avalable about uniformity in polishing, then a certain way of the acceptable ones aimed at the appraisal of contamination nature for building material surface layer contamination can be data reception about the mass and activity of consecutively removed layer samples [4].

To undertake such the experiments the activity of samples was measured beforehand. Then a piece of sandpaper by the size of $3 \mathrm{~cm} \times 10 \mathrm{~cm}$ made on fabric warp was bolted to the holder with holdfasts being fitted in the plastic pack. This pack and the holder were weighted, a sample being under study was fitted inside, and the pack was closed. After sample processing in the locked pack was completed, a dust fraction was deleted from the sample by light taps, and the sample was taken out from the pack. The pack together with a dust fraction from the removed layer of substances were weighted again, and the amount of substance removed from the surface of sample was calculated.
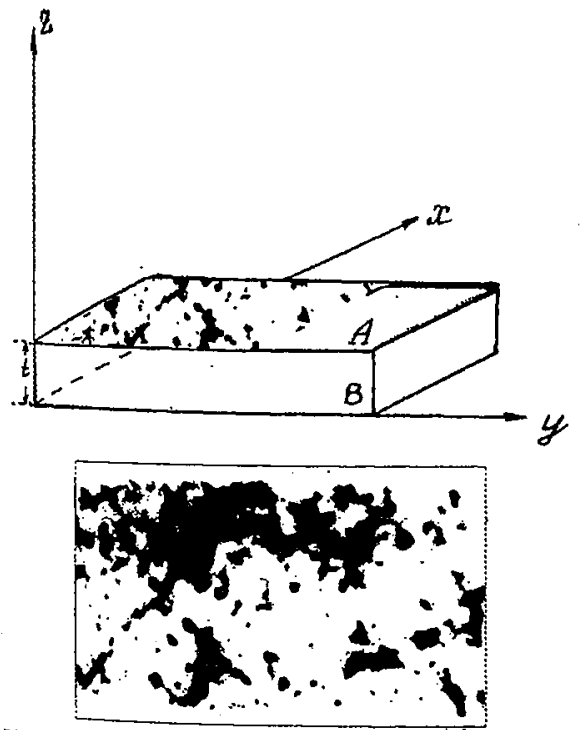

Fig 1. Cross-cut of sample tile

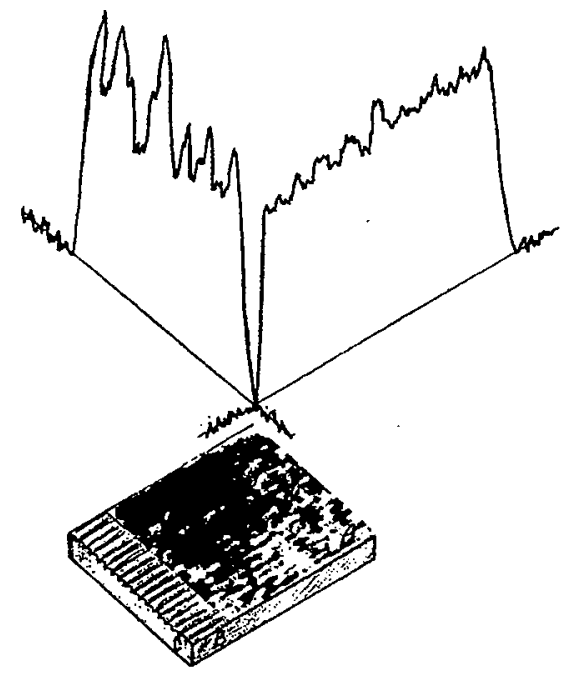

Fig 2. Cross-cut of sample slate

The tile sample was measured again by $\gamma$-spectrometer and the quantity of removed activity was found out. The removed substance of layer was measured by $\gamma$-spectrometer as well. The results received by mechanical processing of the tile sample with checking it by $\gamma$-spectrometer are shown as an example.

From the data received it follows that the most gradient of radionuclide concentration can be observed in the layer the mass of which forms $70-80 \mathrm{~g} / \mathrm{m}^{2}$, i.e. the removal such a mass of layer from the contaminated materials surface gives in our case a significant decontaminating effect. The factor of decontamination reached by this process comes to 1.5-1.6. 
Table 4. Summary table of results of surface layer consecutive removing

\begin{tabular}{|c|c|c|}
\hline No of experiment & Removed layer, $\mathbf{g} / \mathbf{m}^{\mathbf{2}}$ & Portion of activity removals, \% \\
\hline 1 & 20 & 0.16 \\
\hline 2 & 40 & 0.26 \\
\hline 3 & 60 & 0.32 \\
\hline
\end{tabular}

The further removing of deeper layers gives a weaker effect of decontamination, as far as a lagrer part of radionuclides is distributed in the deeper layers of building materials. The most reduction of roughness at tile processing was shown after the first surface processing (table 4). Measurements of removed layer thickness average value herewith had formed about $80 \mu \mathrm{m}$. Juxtaposition of $\beta$-irradiation measurements results of surface before and after decontamination process has allowed to calculate decontamination degree in this case being equal to 0.57 , that corresponds to decontamination factor $\mathrm{K}=2.33$. Subsequent removals of layers had shown that up to $120-140 \mu \mathrm{m}$ of layer thickness the factor of decontamination increases vastly with increasing of removed layer thickness and reaches values 3.5-3.6. Then a growth of decontamination factor is greatly slowed, and it already forms 3.7-3.8 at layer thicknes: being more than $200 \mu \mathrm{m}$, while indicating of that radioactive contamination main part is localized in the layer, the thickness of which for tile forms 100-120 $\mu \mathrm{m}$. The rest less part of radioactive contamination has been penetrated more then $200 \mu \mathrm{m}$, and has a small negative activity gradient at the depths from 100 up to $200-250 \mu \mathrm{m}$. Surface layer roughed nature troubles an accurate determination of its denily. However, even though to suppose with a large fault that surface layer density comes approximately to? $\mathrm{g} / \mathrm{cm}^{3}$, then if the thickness is $120 \mu \mathrm{m}$ the mass of $1 \mathrm{~m}^{2}$ of such a layer will be about $200-250 \mathrm{~g}$.

From the preliminary results has been gained it is possible to get approximate information about the thickness of layer to be removed from the tile, in order to get a significant decontaminating effect. in the considered example it forms near $400-500 \mathrm{~g}$ from each $1 \mathrm{~m}^{2}$ of a tile roof.

It follows from the comparison of roughness measurement and surface $\beta$-radiation before and after the first polishing that a considerable part of activities arranged for the rough surface of building materia is greatly connected with its receptivity to radioactive contamination.

From the results of experiments carried out on efficiency appraisal of decontamination worls conducted on the building materials surface by repeated removing of building material layers, the information can be received about the values of decontamination factor diversity measured also by f. radiation stipulated by the difference in absorbing and $\beta$-radiation by layer material. Divergence betwern decontamination factors as radionuclide penetration arises deep into the material will be increased, and this must be taken in account while undertaking the experimental and practical works on the evaluation of building material decontamination efficiency.

\section{References}

[1] Nicholson, K.W. Deposition of Caesium to Surfaces of Buildings. Radiation-Protection. Dosimetry, v. 21(1-3), 1987.- P. 37-42.

[2] Sandalls, F.J. Radiocaesium on Urban Surfaces after Chernobyl. Radiation-Protection-Dosimetry, v. 21(1-3), 1987.- P. 65-68.

[3] Roed J., K.G. Andersson, H. Prip. Practical Means for Decontamination 9 Years after a Nuclear Accident. Report of RISO, issued in 1995, 81 pp, RIS0 1995

[4] Zlobenko B.P., Yu.G. Fedorenko, L.V. Demchenko, N.P. Movchan., J. Roed, H. Prip. /Study of character of pollution of a superficial layer of building materials //Conference on the Consequences of the Accident at Chernobyl Nuclear Power Plant, 1994. C.59 (in Russian) 